\title{
Strengthening of RC Beam Using Synthetic Fibers and Steel Fibers
}

\author{
${ }^{1}$ P.periyannan, ${ }^{2}$ Mrs.K.J.Jegidha, ${ }^{3}$ DR.S. Suresh Babu \\ Department of Civil Engineering, Adhiyamaan College of Engineering, Hosur, Tamil Nadu, India. \\ 1 periyannan21@gmail.com, ${ }^{2}$ jegi.kj@gmail.com, ${ }^{3}$ sunisurp@gmail.com,
}

ABSTRACT - The fibers are commonly use to enhance concrete's flexural resilience and ductility, and can even remove the need for traditional reinforcement. Steel fibers are more commonly used in structural applications while synthetic fibers are more frequently used due to shrinkage to reduce crack opening. RC beam specimens were constructed with steel and synthetic fiber groups, based on the investigation. The introduction of admixtures was used in steel fibers of hook ends with 50, 60 aspect ratio and crimped round of 52.85 aspect ratio comprising 0 per cent and 0.6 per cent volume fraction. In the group of synthetic fibres $20 \mathrm{~mm}$ cutting thicknes polypropylene fibres. In order to compare the strength aspects of RC beams using synthetic fibers, steel fibers with those of traditional RC beams, this paper validated the positive effect of steel fibers with different aspect ratios and polypropylene fibers with different cut lengths in compression and splitting performance improvement of specimens at 7 and 28 days, examined the sensitivity of different fibers to concrete with flexural strength.

Keywords: Steel fiber, Polypropylene fiber, Compressive strength, fiber reinforced concrete.

\section{INTRODUCTION}

The Fibre Reinforced Concrete (FRC), obtained by adding steel or synthetic fibres to RC beam is be coming widely used in civil engineering because of its favourable properties . In particular, the introduction of fibres gives to concrete a significant tensile residual strength in the and reduces the crack propagation. Fibres are also used to improve the flexural toughness and ductility of concrete. FRC may increases the speed of construction and may even eliminate the need for conventional reinforcement . The characteristics of FRC depend on the properties of the concrete matrix but mostly on the type, the amount and the geometry of the fibres; these parameters, in fact, control the bond between fibres and concrete. Nowadays different types of fibres are available to engineers. The Steel-Fibre Reinforced Concretes (SFRC)are widely used in a range of structural applications such as structural facade panels, industrial floors, precast structural elements, tunnel linings, etc., and in general in all those applications in which concrete cracking control is important. Synthetic fibres are usually manufactured in smaller dimensions with respect to steel fibres and most typically used in industrial floors to reduce cracking induced by shrinkage. Recently, Synthetic Fibre Reinforced Concretes (SFRC) have been developed with the aim of substituting steel fibres in structural applications but the level of knowledge on their mechanical behaviour is still limited. This paper describes the results of an extensive experimental campaign performed at Laboratory of Structural Engineering of the University of Bologna.In this campaign several concrete beams were casted using a concrete reinforced with different types and amounts of steel and synthetic fibres and were tested in a three-point bending scheme. All the beams where casted using the same concrete mix design. The mix composition was defined in apreliminary experimental campaign, in order to have the desired tensile strength. Data obtained during the tests were used to calibrate the parameters of a stress crack opening relation bsy means of an inverse analys is procedure. Concrete is characterized by brittle failure, the nearly complete loss of loading capacity, once failure is initiated. This characteristic, which limits the application of the material, can be overcome by the inclusion of a small amount of short randomly distributed fibers (steel, synthetic and natural) and can be practiced among others that remedy weaknesses of concrete, such as low growth resistance, high shrinkage cracking, low durability, etc..

\section{SYNTHETIC FIBRE}

Synthetic fibres are no substitute for primary reinforcement in concrete because they add little or no strength. But structural reinforcement doesn eet provide its benefits until concrete hardens. That's why some contractors add synthetic fiber to concrete as secondary. Unlike structural reinforcement, synthetic fibers providebenefits while concrete are still plastic. They also enhance some of the properties of hardened concrete.

2.1 SYNTHETIC FIBRE TYPES - The number of synthetic fibre has grown in recent years, the primary types of synthetic fibres commercially available in the 
India are polypropylene, polyester, and nylon. Though the fibres within each type come in various lengths, thicknesses, and geometries, synthetic fibres provide similar benefits when used as secondary concrete reinforcement. Polypropylene- The synthetic fibers available in the United States, polypropylene is the most widely used in ready mixed concrete .Polypropylene fibers are hydrophobic, so they don ${ }^{\text {ee }}$ absorb water and have no effect on concrete mixing water requirements. They come as monofilaments.

STEEL FIBER-The presence of fibers may alter the failure mode of concrete, but the fibers effect will be minor on the improvement of compressive strength values (0 to 15 percent). The strain of SFRC corresponding to peak compressive strength increases as the volume fraction of fibers increases. As aspect ratio increases, the compressive strength of SFRC also increases marginally. As the load increases, the deflection also increases. However the area under the load-deflection curve also increases substantially depending on the type and amount of fibers added.

\subsection{OPC CONCRETE}

The materials required to render OPC concrete. The minimum concrete strength to be used for building is $\mathrm{M} 20$ degree as per I.S: 456- 2000.In this analysis, therefore, the nominal mix needed for M 20 degree 1:1.5:3 is tried. The same blend ratio is also attempted in the concrete geopolymer. The constituents of 8 Molarity sodium hydroxide geopolymer concrete for M 20 grade concrete $(1: 1.5: 3.0)$ is shown in Table 1.

Table 1 Constituents Of SY fiber steel fiberConcrete

\begin{tabular}{|l|l|}
\hline Description & Quantity \\
\hline Cement & $440 \mathrm{~kg} / \mathrm{m} 3$ \\
\hline synthetic fibre & $0.5 \%$ \\
\hline Steel fiber & $0.5 \%$ \\
\hline Water & 0.45 \\
\hline Grade & $\mathrm{M} 20$ \\
\hline Coarse aggregate $<20 \mathrm{~mm}$ & $1350 \mathrm{~kg} / \mathrm{m} 3$ \\
\hline Fine aggregate & $710 \mathrm{~kg} / \mathrm{m} 3$ \\
\hline Curing & 28 days \\
\hline
\end{tabular}

\section{EXPERIMENTAL INVESTIGATION}

The test program consists of casting two beams, and testing them. Beam scale $150 \times 150 \times 100 \mathrm{~mm}$, two of which are cement concrete control beams and geopolymer concrete beams. The beam were planned as reinforced under part. Using $8 \mathrm{~mm}$ diameter stirrups @ $150 \mathrm{~mm} \mathrm{c} / \mathrm{c}$, it is reinforced with 2-12 \# at bottom, 2-10 \# at top. Control cement concrete beams cast with water cement ratio of 0.5 using $\mathrm{M} 20$ grade (1:1.5:3) and Fe415 grade steel. Ordinary Portland cement, natural river sand, and maximum size $20 \mathrm{~mm}$ crushed granite are used for concrete power. Using high yield deformed bars (HYSD) with a diameter between 12 and $10 \mathrm{~mm}$ and the Poisson ratio is found as 0.12 . The respectively known as reinforced cement concrete .

\section{TEST SETUP}

The test specimen is mounded onto a $500 \mathrm{kN}$ capacity beam test frame. The beams are simply supported over a span of $3000 \mathrm{~mm}$ and subjected to symmetrically mounted two combined loads on the base. The load distance is 1000 $\mathrm{mm}$. The load is applied to the support at two points each $500 \mathrm{~mm}$ away from the middle of the beam. Mindset 0.001 $\mathrm{mm}$ dial gages are used to measure deflections below the load points and to measure deflection at the mid-span. The reading on the dialgauge are reported at different loads . A demac scale is used to measure the strain in concrete. An automatic data acquisition unit is used during the test to collect the data.The first loads of crack are obtained through visual exam. The control beam crack patterns (RCC) figure 6.

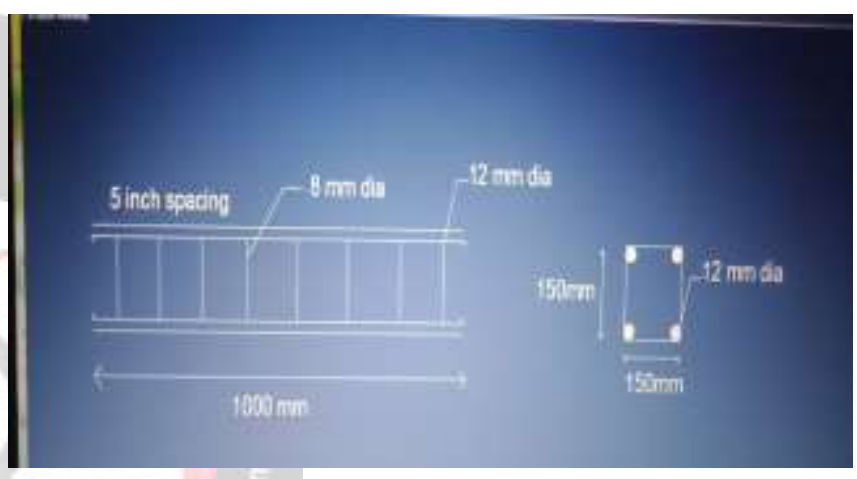

Figure 1. Reinforcement Details

PRELIMINARY TEST IN MATERIAL

Preliminary Test In Material

- Fineness modulus of course agregate $=3.75$

- The specific gravity of course aggregate $=2.7$

- Fineness of cement $=2.33 \%$

- Specific gravity of cement $=3.10$

- Fineness modulus of sand $=2,45$

- Specific gravity of sand $=2.5$

- Aspect ratio steel fiber and SY fiber 250

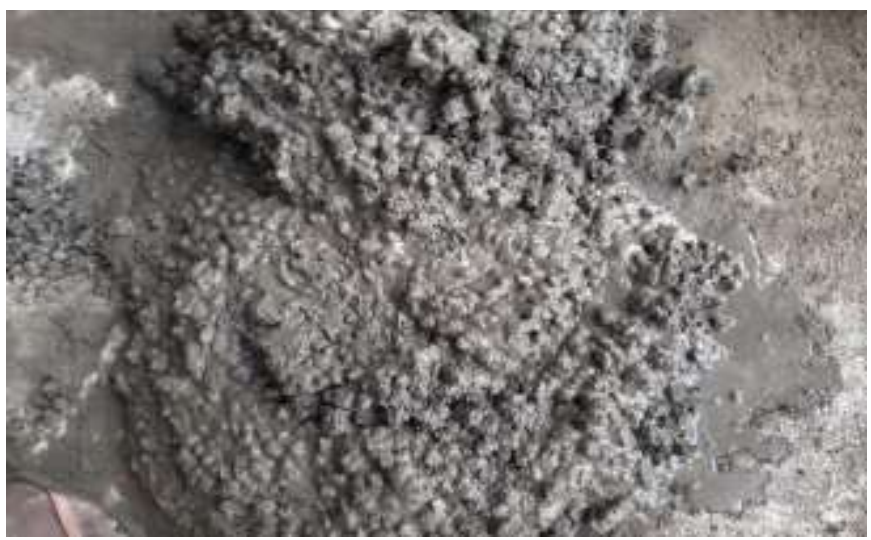

Figure 2. opc concrete 


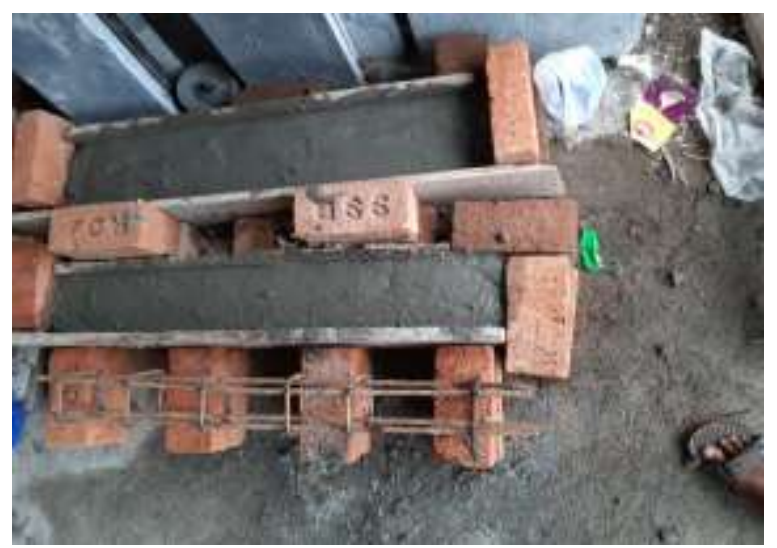

Figure 3. opc casting process

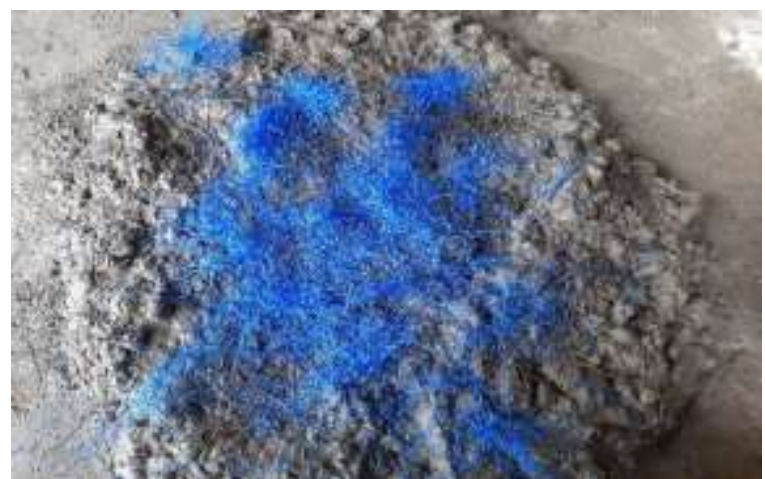

Figure 4. synthetic fibre \& steel fiber concrete mix

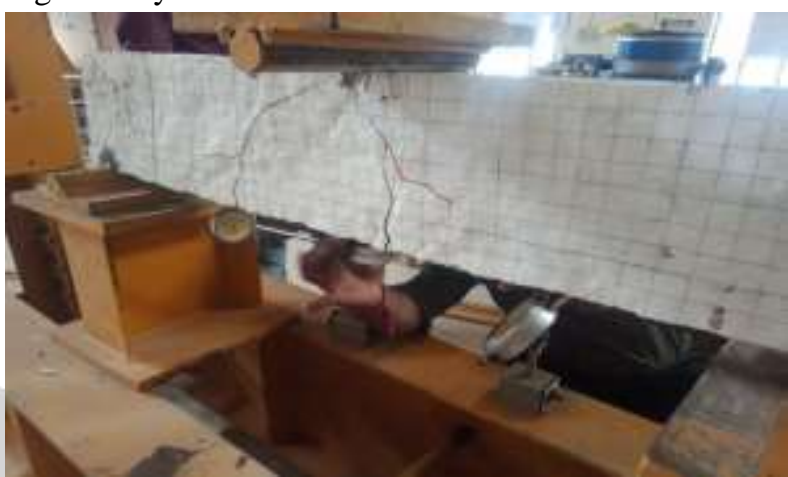

Figure 5. test setup

\begin{tabular}{|l|l|l|l|l|l|l|}
\hline S1 No & Beam & $\begin{array}{l}\text { Initial Crack } \\
\text { Load } \\
(\mathrm{kN})\end{array}$ & $\begin{array}{l}\text { Service } \\
\text { Load } \\
(\mathrm{kN})\end{array}$ & $\begin{array}{l}\text { Yield } \\
\text { Load } \\
(\mathrm{kN})\end{array}$ & $\begin{array}{l}\text { Ultimate } \\
\text { Load } \\
(\mathrm{kN})\end{array}$ & Max. Deflection(mm) \\
\hline 1 & RCC Beam & 14 & 28.5 & 43 & 45 & 60 \\
\hline 2 & $\begin{array}{l}\text { SY\&STEEL } \\
\text { FIBER Beam }\end{array}$ & 19 & 35 & 47.50 & 48,5 & 65 \\
\hline
\end{tabular}
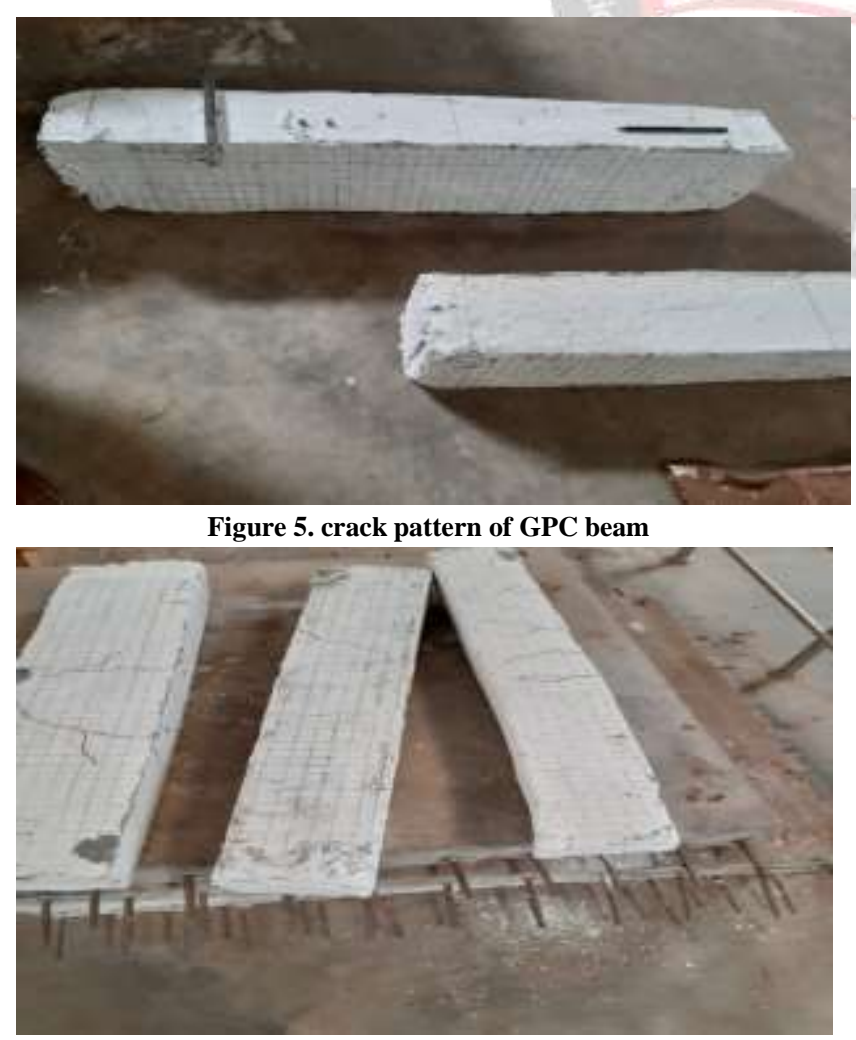

Figure 6. crack pattern of rcc beam

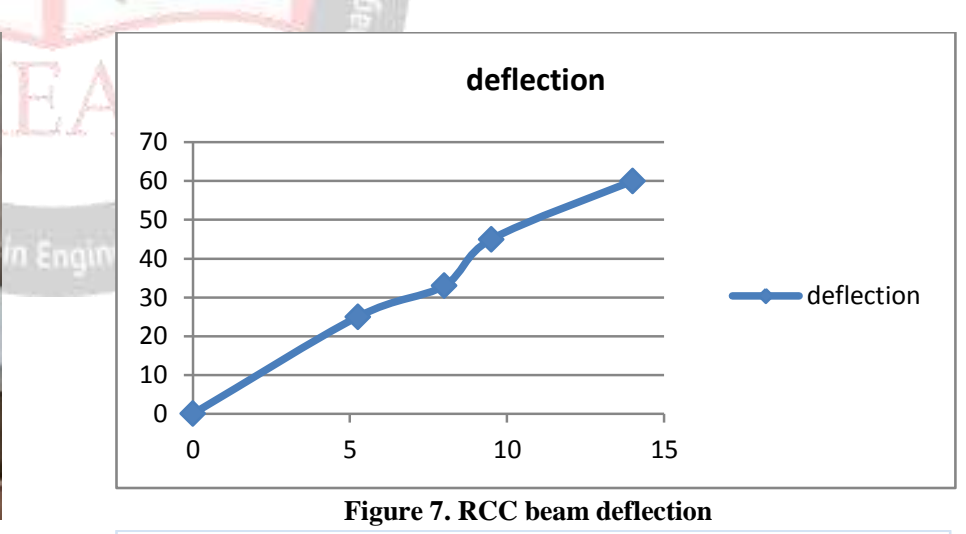

Figure 7. RCC beam deflection

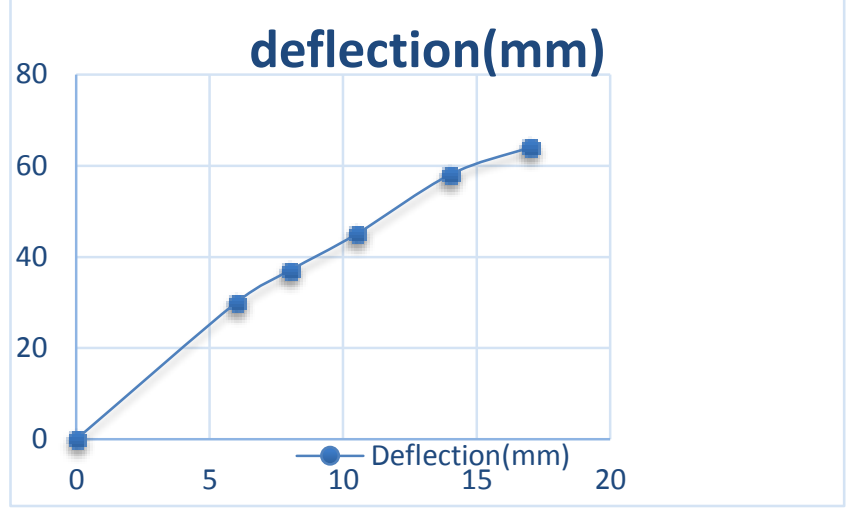

Figure 8. SY \&STEEL FIBER beam deflection 


\section{CONCLUION}

The reinforcement cement concrete and steel fiber concrete have a compressive strength of $28.5 \mathrm{~N} / \mathrm{mm} 2$. sThe geopolymer concrete slump is obtained as $120 \mathrm{~mm}$ even without water adding. The characteristics of load deflection obtained for the RCC beams and GPC beams are curvature that is almost identical. Compared to $\mathrm{RCC}$ beams $(15 \mathrm{kN})$, the first cracking and duty loads $(19 \mathrm{kN})$ of steel fiber beams show slightly greater. synthetic fibre concrete beam flexural activity is more powerful than ordinary beams. The total efficiency of synthetic fibre beams is greater than RCC beams

1. SFRC beam, the strength increasing $30 \%$ comparing to conventional RC beam.

2. Combination of raw materials (synthetic fibers \& $\mathrm{SF}$ ) results in significant strength gaining characteristics.

3. synthetic fibers such as steel fibers and polypropylene fibers are used as a secondary reinforcement to obtain the strength of steel fiber for compressive strength and synthetic fibers for tensile strength

4. steel fibers used in concrete were result in increase in compressive strength of concrete especially $1 \%$ steel fiber added to the volume of cement is found to be optimum.

\section{REFERENCES}

[1] m.a.tantra "performance of beam-column joint using steel fibers" international journal of innovative technology and exploring engineering (ijitee) issn: 2278-3075, volume-8 issue- 8 june, 2019

[2] ms. shweta a. sajjanshetty, ms. rupali b. kejkar " flexural behavior of strengthened and repaired r.c. beams by using steel and coir fiberconcrete jacket" international journal of engineering research \& technology (ijert) march 2014

[3] laya a, " margaret abraham an experimental investigation on basalt reinforced beam using steel fibers" international journal of applied engineering research issn 0973-4562 volume 14, number 12, 2019

[4] shahid iqbal a,c, ahsan ali a, klaus holschemacher a, thomas a. bier b, abid a. shah "strengthening of rc beams using steel fiber reinforced high strength lightweight self-compacting concrete (shlscc) and their strength predictions" materials and design 100 (2016) 37-46 e-issn 0976-3945 vol 2

[5] shivani bhardwaj1, mandeep kau" strengthening of steel fiber reinforced beams using gfrp" international research journal of engineering and technology (irjet) 09002 (2014) page 69 vol 4

[6] mohammed a. sakr1, ayman a. sleemah1, tarek m. khalifa1, walid $n$. mansour behavior of rc beams strengthened in shear with ultra-high performance fiber reinforced concrete (uhpfrc) matec web of conferences vol 4 199, (2018)

[7] zhiguo youa,b, xiangyu chenc, shuai dong "ductility and strength of hybrid fiber reinforced self-consolidating concrete beam with low reinforcement ratios" 2011 international conference on management (rem) 2015 vol 5

[8] amit rai1, dr. y.p joshi" applications and properties of fibre reinforced concrete "issn : 2248-9622, vol. 4, issue 5( version 1), may 2014, pp.123-131, pp 25-30

[9] sandeep kumar 1.s, dr.h.n.jagannatha reddy, rumina nizar "retrofitting of rc beams using natural frp wrapping (nsfrp)" international journal of emerging trends in engineering and development, sept 2013 vol. 1(2), pp. 27-42

[10] jun-mo yang, kyung-hwan min, hyun-oh effect of steel and synthetic fibers on flexural behavior of high-strength concrete beams reinforced with frp composites: part b 43 (2012) 1077-1086, 10 january 2012

[11] vikrant s. vairagade a and kavita s. ken" strength of normal concrete using metallic and synthetic fiber" procedia engineering 51 ( 2013 ) 132 - 140,2012

[12] teuku budi auliaa,*, rinald bending capacity analysis of high-strength reinforced concrete beams using environmentally friendly synthetic fiber composite procedia engineering 125 ( 2015 ) 1121 - 1128, 2015

[13] hang hu, panos papastergiou, harris angelakopoulos , maurizio guadagnini, kypros pilakoutas mechanical properties of sfrc using blended manufactured and recycled tyre steel fibres construction and building materials 163 (2018) 376-389, dec 2017 vol 3

[14] a. sofi , b.r. phanikumar" an experimental investigation on flexural behaviour of fibre-reinforced pond ash-modified concrete"ain shams engineering journal (2015) 6, 11331142, april 2015 7(4),

[15] libo yan , nawawi chouw'experimental study of flax frp tube encased coir fibre reinforced concrete composite colum" construction and building materials 40 (2013) 1118-1127, dec2012 pp.57-61.

[16] gonzalo ulzurrun , carlos zanuy 'flexural response of sfrc under impact loading"construction and building materials 134 (2017) 397-411, dec 2016 vol.5, issue 1(2013)24-31.

[17] masoud ghahremannejad, maziar mahdavi, arash emami saleh, sina abhaee, ali abolmaali "experimental investigation and identification of single and multiple cracks in synthetic fiber concrete beams"masoud ghahremannejad, maziar mahdavi, arash emami saleh, sina abhaee, ali abolmaali "case studies in construction materials 9 (2018) e00182 jul2018

[18] k.rajeshkumar , n.mahendran ,r. gobinath "experimental studies on viability of using geosynthetics as fibers in concrete"international journal of applied engineering research, dindigul volume-7, issue-6c2, april 2019.

[19] k. tamilselvan, dr. n. balasundaram "experimental investigation on flexural behavior of hybrid fiber reinforced concrete beam"international journal of civil engineering and technology (ijciet) composite procedia engineering 125 ( 2015 ) 1121 - 1128, 2014

[20] prakash mondal, dilip kumar singha roy" strengthening of reinforced concrete beam using steel fiber at different depth of the beam"international journal of research in engineering and technology, Vol. 8, Issue 4, 2017, Pp. 1905-1917. 